\title{
Comparison of the performance of several recent hydrogen combustion mechanisms
}

\author{
I. Gy. Zsély, C. Olm, R. Pálvölgyi, T. Varga, T. Nagy, T. Turányi * \\ Institute of Chemistry, Eötvös University (ELTE), Budapest, Hungary
}

\begin{abstract}
A large set of experimental data was collected for hydrogen combustion: ignition measurements in shock tubes (786 data points in 54 datasets) and rapid compression machines (166 data points in 9 datasets), flame velocity measurements (631 data points in 71 datasets) and concentration-time profiles in jet-stirred reactors (152 data points in 9 datasets), covering wide ranges of temperature, pressure and equivalence ratio. The performance of 19 recently published hydrogen combustion mechanisms was tested against these experimental data and the dependence of accuracy on the types of experiment and the experimental conditions was investigated.
\end{abstract}

\section{Introduction}

The reaction steps of hydrogen combustion form a central part of the high temperature combustion of all hydrocarbons and oxygenates. Also, hydrogen is an important fuel itself in areas like carbon-free economy, safety issues, and rocket propulsion. In accordance with its high significance, several new hydrogen combustion mechanisms were published even in the last decade. In these publications, the agreement between the measurements and the simulations is usually characterized by plots, in which the experimental data and the simulation results are depicted together. However, quantitative agreement of the simulation results with the experimental data has not been investigated.

\section{Experimental data}

A large set of experimental data was collected in which the combustion of hydrogen was investigated. This type of measurements, called indirect measurements or bulk measurements, is used for testing detailed reaction mechanisms. We utilized all measurements that were used for testing the recent mechanisms of Ó Conaire et al. [1], Konnov [2], Hong et al. [3] , Burke et al. [4], and Kéromnès et al. [5]. The references for measurements were collected from these recent review articles, but the experimental data were digitalized from the original experimental publications. Also, a comprehensive search was carried out to find all measurements that can be used for testing hydrogen combustion mechanisms. Our data collection is much wider-ranging than any other set of data that has ever been used for testing hydrogen combustion mechanisms.

The data include ignition measurements in shock tubes (786 data points in 54 datasets from 15 original publications) and rapid compression machines (166 data points in 9 datasets from one publication), flame velocity measurements (631 data points in 71 datasets from 20 publications) and concentration-time profiles in jet-stirred reactors (152 data points in 9 datasets from one publication). A dataset contains those data points

\footnotetext{
*Corresponding author: turanyi@ chem.elte.hu Proceedings of the European Combustion Meeting 2013
}

that were measured on the same apparatus at the same time at similar conditions except for one factor that was systematically changed. One experimental publication usually contains one or a few datasets.

All experimental data were encoded in PrIMe file format [6], which is an XML scheme used for the systematic storage of various kinds of combustion experiments. Encoding the experimental conditions and results in PrIMe format allows an automatic simulation of all experiments. A MATLAB code was written that reads the PrIMe datafile and prepares CHEMKIN-II [7] input files. The MATLAB code then starts the corresponding CHEMKIN simulation code (SENKIN, PREMIX or PSR), collects the simulation result and evaluates the agreement between the experimental and simulation results. In principle, the complete investigation of a mechanism against several thousand of very different experimental data can be carried out in a single run. The chemical mechanism was then replaced and the same procedure was repeated with another mechanism. The MATLAB code saved the simulation results in Excel tables.

\section{Methodology}

In this work the agreement of experimental and simulation results is investigated using the following objective function:

$$
\begin{gathered}
E_{i}=\frac{1}{N_{i}} \sum_{j=1}^{N_{i}}\left(\frac{Y_{i j}^{\text {sim }}-Y_{i j}^{\text {exp }}}{\sigma\left(Y_{i j}^{\text {exp }}\right)}\right)^{2} \\
E=\frac{1}{N} \sum_{i=1}^{N} E_{i}
\end{gathered}
$$

where

$$
Y_{\mathrm{ij}}=\left\{\begin{array}{cl}
y_{i j} & \text { if } \sigma\left(y_{i j}^{\mathrm{exp}}\right) \approx \text { constant } \\
\ln y_{i j} & \text { if } \sigma\left(\ln y_{\mathrm{ij}}^{\text {exp }}\right) \approx \text { constant }
\end{array}\right.
$$

Here $N$ is the number of datasets and $N_{i}$ is the number of data points in the $i$-th dataset. Values $y_{i j}^{\exp }$ and $\sigma\left(y_{i j}^{\exp }\right)$ are the $j$-th data point and its standard deviation, respectively, in the $i$-th measurement series. The 
corresponding simulated (modelled) value is $Y_{i j}^{\text {sim }}$ obtained from a simulation using an appropriate detailed mechanism. $Y_{i j}=y_{i j}$, if the measured value have absolute error (independent of the value of $y_{i j}$, we used this option for laminar flame velocities and measured concentrations. We used option $Y_{i j}=\ln \left(y_{i j}\right)$, if the experiments have relative error (proportional to the value of $y_{i j}$ ), which is characteristic for ignition time measurements. Error function values $E_{i}$ and $E$ would be equal to one if the chemical kinetic model were accurate, and the deviations of the measured and simulated results were caused by the scatter of the experimental data only. This objective function is very similar to the one that has been used at the estimation of rate parameters from experimental data [8], [9].

\section{Mechanisms}

Our aim was to test all hydrogen combustion mechanisms that were published in the last decade. Table 1 contains the list of these mechanisms.

Table 1. The investigated reaction mechanisms

\begin{tabular}{|c|l|l|l|l|}
\hline No. & Mechanism & ref. & species & reactions \\
\hline 1 & Kéromnès 2013 & {$[5]$} & 12 & 33 \\
\hline 2 & Li 2007 & {$[10]$} & 11 & 25 \\
\hline 3 & Ó Conaire 2004 & {$[1]$} & 10 & 21 \\
\hline 4 & Konnov 2008 & {$[2]$} & 10 & 33 \\
\hline 5 & $\begin{array}{l}\text { NUIG NGM } \\
\text { c5_49 2010 }\end{array}$ & {$[11]$} & 11 & 21 \\
\hline 6 & $\begin{array}{l}\text { Saxena } \\
\text { Williams 2006 }\end{array}$ & {$[12]$} & 11 & 21 \\
\hline 7 & Burke 2012 & {$[13]$} & 11 & 27 \\
\hline 8 & Davis 2005 & {$[14]$} & 11 & 25 \\
\hline 9 & Hong 2011 & {$[15]$} & 10 & 31 \\
\hline 10 & USC II 2007 & {$[16]$} & 10 & 28 \\
\hline 11 & CRECK 2012 & {$[17]$} & 11 & 21 \\
\hline 12 & Sun 2007 & {$[18]$} & 11 & 32 \\
\hline 13 & San Diego 2011 & {$[19]$} & 11 & 21 \\
\hline 14 & GRI 3.0 1999 & {$[20]$} & 10 & 29 \\
\hline 15 & $\begin{array}{l}\text { Rasmussen } \\
\text { 2008 }\end{array}$ & {$[21]$} & 10 & 30 \\
\hline 16 & Ahmed 2007 & {$[22]$} & 10 & 20 \\
\hline 17 & Starik 2009 & {$[23]$} & 12 & 26 \\
\hline 18 & Zsély 2005 & {$[24]$} & 10 & 32 \\
\hline 19 & Dagaut 2003 & {$[25]$} & 9 & 21 \\
\hline & & & \\
\hline
\end{tabular}

Several of these mechanisms were originally developed for the description of hydrogen combustion, but we investigated also other mechanisms that were developed for wet CO combustion ([5], [12], [14], [17], [18], [24]), or the combustion of hydrocarbons or oxygenates ([10], [11], [16], [19], [20], [22], [25]). For the latter mechanisms, Table 1 refers to the number of species and reaction of the hydrogen combustion part of these mechanisms. Unlike the other mechanisms, the one of Dagaut et al. includes neither $\mathrm{Ar}$ nor $\mathrm{He}$ as possible bath gases. This affects the comparison with respect to ignition delay times and flame velocities, since argon or helium was used as a bath gas in many experiments. Therefore the results corresponding to this mechanism appears only in Figure 4, where a comparison based on the same subset of data is possible.

\section{Results and Discussion}

The results of the testing are sorted according to the types of experiments.

\section{1) ignition delays in RCMs and shock tubes}

Figure 1 shows that about half of the investigated mechanisms provide a similarly good reproduction of the measured ignition delay times. The worst mechanisms in this respect are those of Zsély 2005, Ahmed 2007, and Starik 2009. Note, that the Zsély 2005 mechanism [24] contains the rate parameters recommended by Baulch et al. [26] without modification. This shows that although the Baulch et al. evaluated rate parameter values are widely used at the creation of combustion mechanisms, further tuning is needed for a good description of ignition delay times in the hydrogen combustion system.

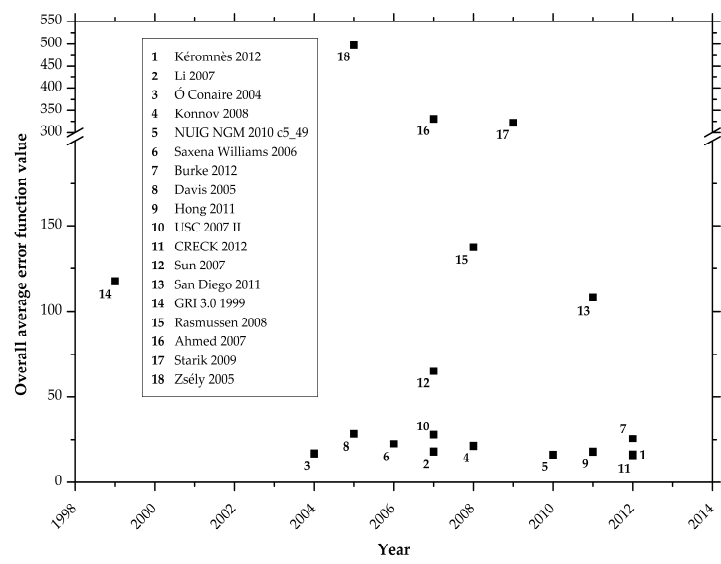

Fig. 1. Overall performance of the mechanisms on ignition delay measurements $v s$. year of publication.

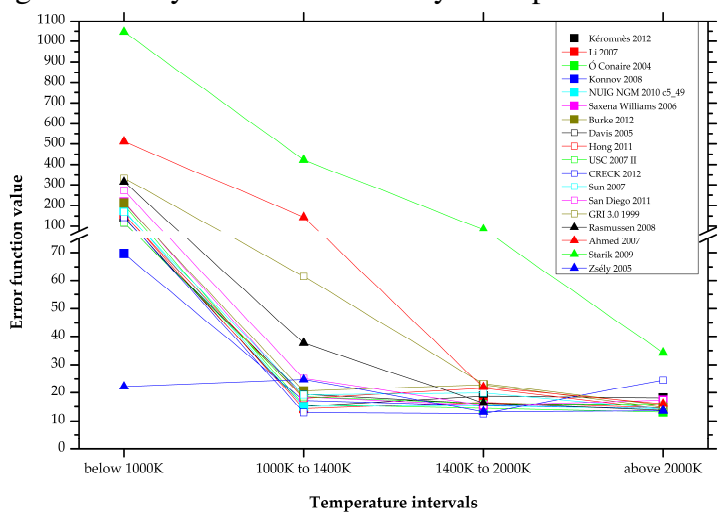

Fig. 2. Performance of the mechanisms on ignition delay measurements in shock tubes for various ranges of temperature. 


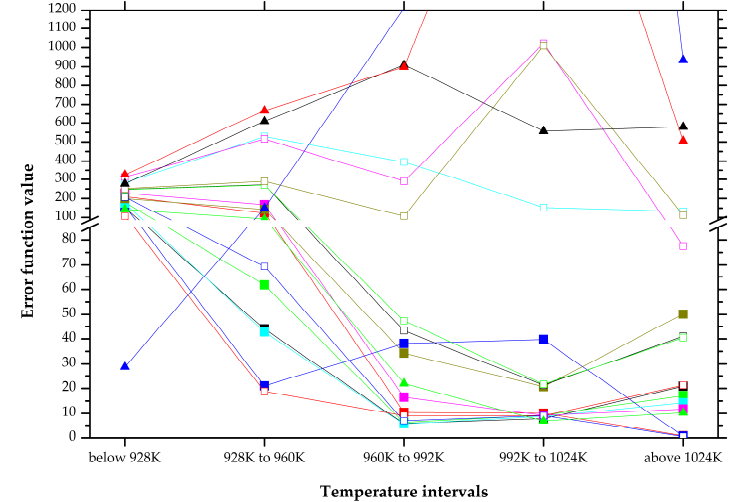

Fig. 3. Performance of the mechanisms on ignition delay measurements in rapid compression machines for various ranges of temperature.

Figures 2 and 3 show the performance of the mechanisms on ignition delay measurements according to ranges of temperature in shock tubes and rapid compression machines, respectively. Most mechanisms reproduce the shock tube experiments similarly well above $1000 \mathrm{~K}$, while below $1000 \mathrm{~K}$ the reproduction of the measured ignition delay times is poor. This behaviour could be associated to the facility effect. Low-temperature shock tube experiments should be handled with special care by taking into account the pressure change during the induction period [27]. The pressure changes were recorded in the rapid compression experiments. However, none of the mechanisms was able to reproduce the low-temperature RCM measurements. Some mechanisms cannot reproduce any of the RCM experiments. Yet, several mechanisms are good in the simulation of these experiments above $960 \mathrm{~K}$.

\section{2) Outlet concentrations in jet stirred reactors}

Figure 4 shows the performance of the mechanisms on the reproduction of measured outlet concentrations in a jet stirred reactor. Here most mechanisms have a similar performance, the only poor performer is the Starik 2009 mechanism.

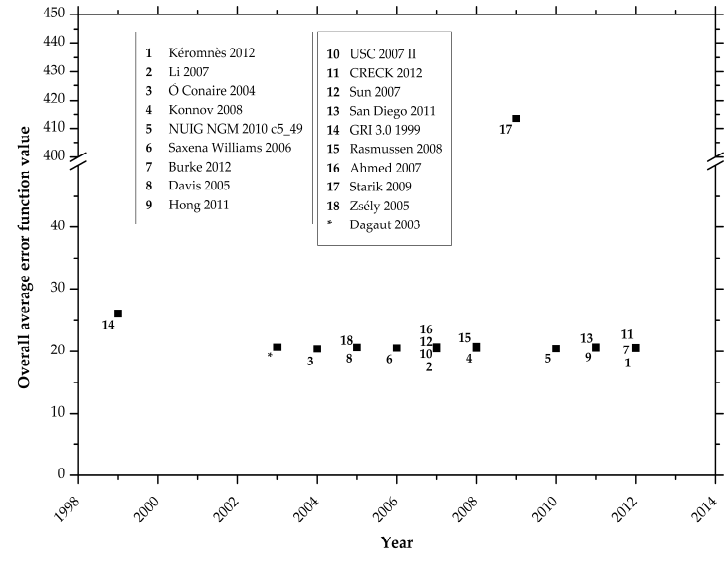

Fig. 4. Overall performance of the mechanisms on JSR measurements $v s$. year of publication.

\section{3) Flame velocity measurements}

Unlike in the ignition delay and JRS measurements, in several flame velocity determinations helium was used as bath gas. Only mechanisms having helium bath gas option were used for the simulation of these experiments, which are about one sixth of all flame velocity measurements. To keep the full comparability of the results, the general comparison (presented in Figure 5) was done without these experiments, but they appear in the comparisons according to the experimental conditions.

Reproduction of the flame velocity measurements show a much wider variety, compared to the ones of ignition delay times and JSRs. The best mechanisms were Davis 2005, Saxena Williams 2006, Li 2007, Konnov 2008 and Kéromnès 2013. The CRECK 2012 mechanism was able to reproduce the least the measured flame velocity results.

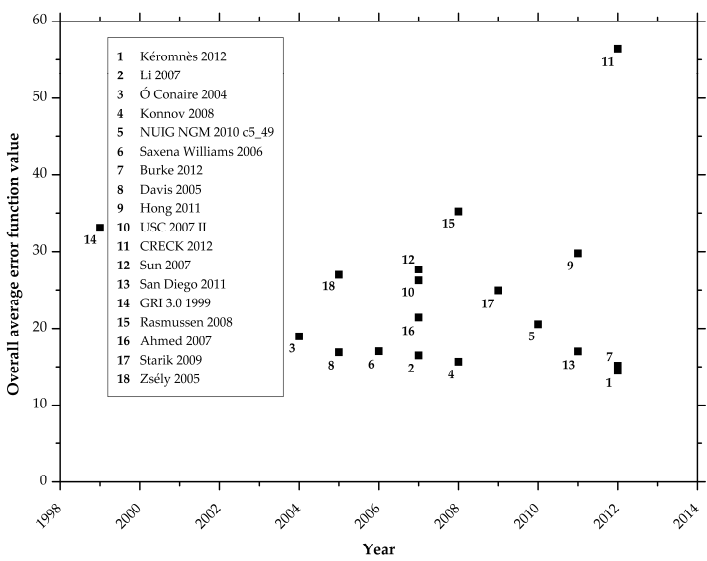

Fig. 5. Overall performance of the mechanisms on flame velocity measurements $v s$. year of publication. 


\section{Dependence of the error of simulated flame velocity on the experimental conditions}

Figure 6 shows the error of the reproduction of the measured flame velocities in the various ranges of pressure. The general trend is that the error of reproduction slightly decreases with increasing pressure. Most mechanisms, like those of Davis 2005 and Burke 2012 show a uniform low deviation over all ranges of pressure. The worst performing mechanism here is the GRI 3.0 1999, since its error significantly increases with increasing pressure. The legends used in Figures 6 to 8 are identical to those used in Figure 2.

The flame velocities are measured by four different types of methods. These are the flame cone method (for a discussion of this method see e.g. [28]), the outwardly propagating spherical flame method [29], the counterflow twin-flame method [30], and the heat flux burner method [31]. Figure 7 demonstrates that the reproduction of the experimental data measured with these methods improves in the order above. Experimental data measured with the flame cone method are especially poorly reproduced.

Figure 8 investigates the performance of the mechanisms on flame velocity measurements according to the type of the bath gas. Interestingly, the error is the smallest when the bath gas is a mixture of $\mathrm{N}_{2}$ and Ar. For the other types of bath gases (like pure $\mathrm{N}_{2}, \mathrm{Ar}$, or $\mathrm{He}$, or using $\mathrm{N}_{2} / \mathrm{He}$ mixtures) the errors are slightly higher. Six mechanisms (Davis 2005, Li 2007, Konnov 2008, San Diego 2011, Burke 2012, Kéromnès 2012) perform well for most types of bath gases, while other methanisms (like NUIG NGM c5_49 2010, Hong 2011, CRECK 2012) perform well for one type of bath gas and poorly for another bath gas.

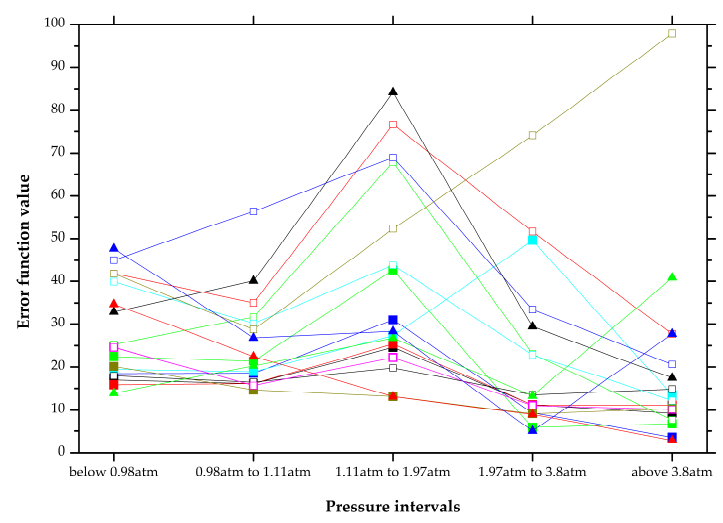

Fig. 6. Performance of the mechanisms on flame velocity measurements for various ranges of pressure.

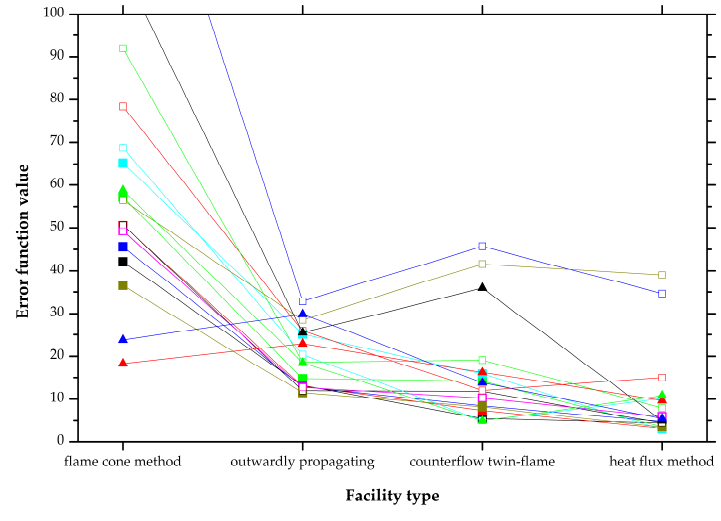

Fig. 7. Error of the reproduction of the flame velocity according to the type of measurement.

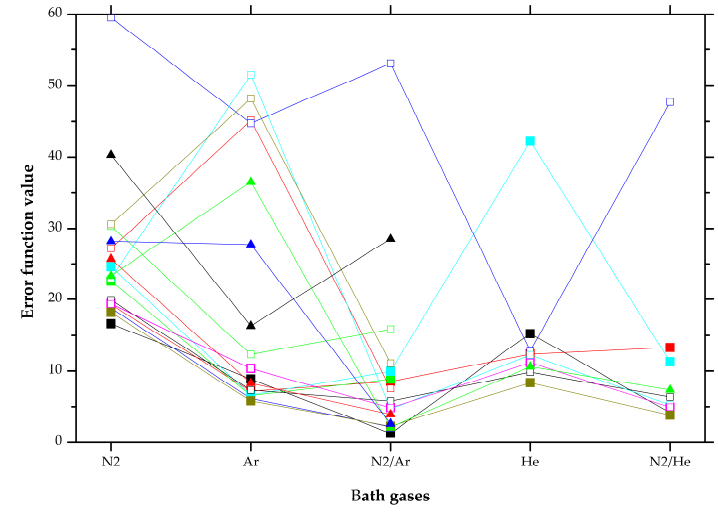

Fig. 8. Performance of the mechanisms on flame velocity measurements according to the type of the bath gas.

\section{Conclusions}

The accurate description of the combustion of hydrogen is important from both scientific and industrial points of view. Several excellent reviews were published recently [1-5], which discuss new developments in this field. However, a comprehensive investigation and comparison of all recent hydrogen combustion mechanism have not been published.

The best mechanisms for the reproduction ignition delay times, JSR experiments and flame velocity measurements are CRECK 2012, Ó Conaire 2004 and Kéromnès 2013, respectively. Several mechanisms do not work properly at high/low ranges of equivalence ratio, temperature, and pressure. Results, such as those presented in Figures 2, 3, 6 and 8, may help the selection of a mechanism for simulations to be carried out at some given conditions.

Figure 9 shows the performance of each mechanism, tested against all collected experimental data. This figure indicates that the performance of the Kéromnès 2013 mechanism is currently the best, but several other mechanisms, like the Ó Conaire 2004, Li 2007, Konnov 
2008 and NUIG NGM c5_49 2010 have similarly good overall performance. However, it is not advised to use the mechanisms of Zsély 2005, Ahmed 2007 and Starik 2009 for hydrogen combustion simulations.

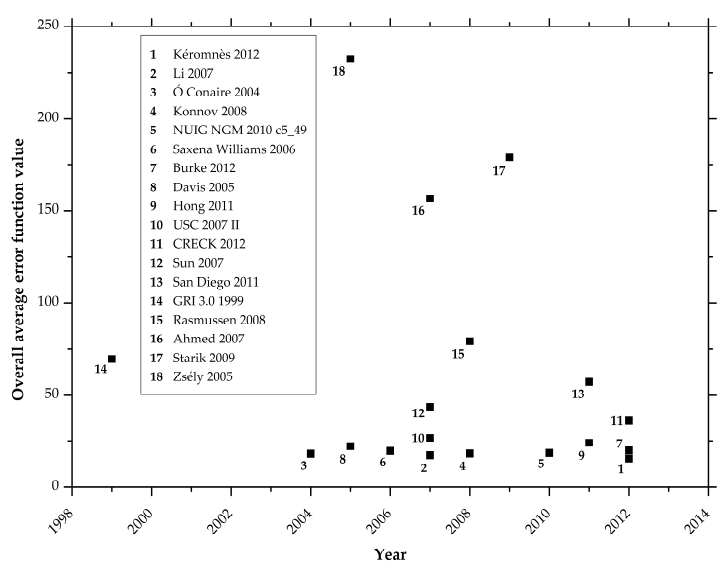

Fig. 9. Performance of the mechanisms considering all experimental data $v s$. year of publication.

\section{Acknowledgements}

The authors acknowledge the contribution of Dr. Mátyás Cserháti to the collection of experimental data, the helpful discussions with Prof. Henry Curran, and the financial support of OTKA grants K84054 and NN100523. The authors are also grateful for the supportive discussions with the partners in COST collaboration CM0901 Detailed Chemical Models for Cleaner Combustion.

\section{References}

[1] M. Ó Conaire, H. J. Curran, J. M. Simmie, W. J. Pitz, C. K. Westbrook, Int. J. Chem. Kinet. 36 (2004) 603-622.

[2] A. A. Konnov, Combust. Flame 152 (2008) 507528.

[3] Z. Hong, D. F. Davidson, R. K. Hanson, Combust. Flame 158 (2011) 633-644.

[4] M. Burke, M. Chaos, Y. Ju, F. L. Dryer, S. Klippenstein, Int. J. Chem. Kinet. 44 (7) (2012) 444474.

[5] A. Kéromnès, W. K. Metcalfe, K. Heufer, N. Donohoe, A. Das, C. J. Sung, J. Herzler, C. Naumann, P. Griebel, O. Mathieu, M. C. Krejci, E. L. Petersen, W. J. Pitz, H. J. Curran, Combust. Flame 160 (2013) 9951011.

[6] M. Frenklach, PrIMe Database, http://www.primekinetics.org/.).

[7] R. J. Kee, F. M. Rupley, J. A. Miller, in: Sandia National Laboratories: 1989.

[8] T. Turányi, T. Nagy, I. G. Zsély, M. Cserháti, T. Varga, B. T. Szabó, I. Sedyó, P. T. Kiss, A. Zempléni, C. H. J., Int. J. Chem. Kinet. 44 (2012) 284-302.

[9] I. G. Zsély, T. Varga, T. Nagy, M. Cserháti, T. Turányi, S. Peukert, M. Braun-Unkhoff, C. Naumann, U. Riedel, Energy 43 (2012) 85-93.
[10] J. Li, Z. Zhao, A. Kazakov, M. Chaos, F. L. Dryer, J. J. J. Scire, Int. J. Chem. Kinet. 39 (2007) 109-136.

[11] D. Healy, D. M. Kalitan, C. J. Aul, E. L. Petersen, G. Bourque, H. J. Curran, Energy \& Fuels 24 (2010) 1521-1528.

[12] P. Saxena, F. A. Williams, Combust. Flame 145 (2006) 316-323.

[13] M. P. Burke, M. Chaos, Y. Ju, F. L. Dryer, S. J. Klippenstein, Int. J. Chem. Kinet. 44 (2012) 444-474. [14] S. Davis, A. Joshi, H. Wang, F. Egolfopoulos, Proc. Combust. Inst. 30 (2005) 1283-1292.

[15] Z. Hong, D. Davidson, R. Hanson, Combust. Flame 158 (2011) 633-644.

[16] H. Wang, X. You, A. V. Joshi, S. G. Davis, A. Laskin, F. Egolfopoulos, C. K. Law USC Mech Version II. High-temperature combustion reaction model of $\mathrm{H} 2 / \mathrm{CO} / \mathrm{C} 1-\mathrm{C} 4$ compounds.

http://ignis.usc.edu/USC_Mech_II.htm

[17] CRECK modeling group. Hydrogen/CO mechanism version 1201 .

http://creckmodeling.chem.polimi.it/

[18] H. Sun, S. I. Yang, G. Jomaas, C. K. Law, Proc. Combust. Inst. 31 (2007) 439-446.

[19] Chemical-Kinetic Mechanisms for Combustion Applications, San Diego Mechanism web page, Mechanical and Aerospace Engineering (Combustion Research), University of California at San Diego, version 2011-11-22. http://combustion.ucsd.edu [20] G. Smith, D. Golden, M. Frenklach, N. Moriary, B. Eiteneer, M. Goldenberg, C. Bowman, R. Hanson, S. Song, W. Gardiner, V. lissianski, Z. Qin GRI-Mech 3.0, http://www.me.berkeley.edu/gri_mech/.

[21] C. L. Rasmussen, J. Hansen, P. Marshall, P. Glarborg, Int. J. Chem. Kinet. 40 (2008) 454-480.

[22] S. S. Ahmed, F. Mauß, G. Moréac, T. Zeuch, Phys. Chem. Chem. Phys. 9 (2007) 1107-1126.

[23] A. M. Starik, N. S. Titova, A. S. Sharipov, V. E. Kozlov, Combust. Explos. Shock Waves 46 (2010) 491-506.

[24] I. G. Zsély, J. Zádor, T. Turányi, Proc. Combust. Inst. 30 (2005) 1273-1281.

[25] P. Dagaut, F. Lecomte, J. Mieritz, P. Glarborg, Int. J. Chem. Kinet. 35 (2003) 564-575.

[26] D. L. Baulch, C. T. Bowman, C. J. Cobos, R. A. Cox, T. Just, J. A. Kerr, M. J. Pilling, D. Stocker, J. Troe, W. Tsang, R. W. Walker, J. Warnatz, J. Phys. Chem. Ref. Data 34 (2005) 757-1397.

[27] G. A. Pang, D. F. Davidson, R. K. Hanson, Proc. Combust. Inst. 32 (2009) 181-188.

[28] G. E. Andrews, D. Bradley, Combust. Flame 18 (1972) 133-153.

[29] D. Bradley, P. H. Gaskell, X. J. Gu, Combust. Flame 104 (1996) 176-198.

[30] C. K. Wu, C. K. Law, Proc. Combust. Inst. 20 (1984) 1941-1949.

[31] L. P. H. de Goey, A. van Maaren, R. M. Quax, Combust. Sci. Technol. 92 (1993) 201-207. 